Article

\title{
The Influence of Thermal Properties Anisotropy on Subtractive Laser Processing of $\mathrm{B}_{4} \mathrm{C} / \mathrm{h}-\mathrm{BN}$ Composites
}

\author{
Paweł Rutkowski * (1), Karol Gala, Kamila Misiura and Jan Huebner \\ Department of Ceramics and Refractories, Faculty of Materials Science and Ceramics, AGH University of \\ Science and Technology in Krakow, al. Mickiewicza 30, 30-059 Kraków, Poland; wattslaw.gala@gmail.com (K.G.); \\ kamilamajamisiura@gmail.com (K.M.); huebnerj@agh.edu.pl (J.H.) \\ * Correspondence: pawel.rutkowski@agh.edu.pl or pawelr@agh.edu.pl
}

Received: 5 October 2020; Accepted: 10 November 2020; Published: 17 November 2020

\begin{abstract}
This work concerns boron carbide matrix composites with the addition of hexagonal boron nitride particles (h-BN) as a solid lubricate. The composite materials were hot-pressed and analysed in terms of phase, structure, and microstructure changes in relation to the h-BN content. The uniaxial pressure applied during the manufacturing process allowed the orientation of single h-BN particles and its agglomerates in perpendicular direction to the pressing axis. The anisotropy of heat transfer and thermal expansion coefficient (CTE) and density changes in relation to temperature are discussed. Thermal diffusivity and conductivity were measured in relation to the material direction by the laser flash analysis method (LFA). In this paper, understanding the heat flow and CTE changes allowed explaining the results of investigated subtractive laser processes of the manufactured composites. The laser ablation process was conducted on $\mathrm{B}_{4} \mathrm{C} / \mathrm{h}-\mathrm{BN}$ composites in parallel and perpendicular direction to each other. It was done in a continuous work (CW) mode at $50 \mathrm{~W}$ with a $40 \mu \mathrm{m}$ spot and $3 \mathrm{~mm} / \mathrm{s}$ beam travel speed. The influence of h-BN particles and their orientation on thermal properties is discussed. The effect of laser processing on $\mathrm{B}_{4} \mathrm{C} / \mathrm{h}-\mathrm{BN}$ composites was also discussed in relation to the material surface roughness measured with a confocal microscope, microstructure observations, density, and thermal properties changes in relation to the material direction.
\end{abstract}

Keywords: boron carbide; hexagonal boron nitride; anisotropy; thermal properties; solid lubricate; laser processing; ceramic matrix composite

\section{Introduction}

The boron carbide is a low density material of $2.51 \mathrm{~g} / \mathrm{cm}^{3}$ with rhombohedral crystallographic structure including a high melting point of about $2400{ }^{\circ} \mathrm{C}$, very high hardness of $38 \mathrm{GPa}$, a good elastic, excellent wear and mechanical properties, and high neutron absorption cross section [1-4]. Due to these properties, it is widely used as sand blasting nozzles, armor plates, sliding rings, neutron-shielding materials in nuclear industry, milling agents, grinding material, hard coatings, and also boron neutron capture therapy (BNCT) [5-9].

The hexagonal boron nitride, also called white graphite, was very often investigated by researchers due to the possibilities to decrease the friction coefficient for cutting tools and bearing sliding applications $[10,11]$. This phase has been inserted into various oxides, nitrides, and carbides of advanced ceramic materials, for example: $\mathrm{Si}_{3} \mathrm{~N}_{4}, \mathrm{SiC}, \mathrm{Al}_{2} \mathrm{O}_{3}, \mathrm{~B}_{4} \mathrm{C}$, SiAlON.

The first works concerning anisotropic properties of $\mathrm{B}_{4} \mathrm{C}-\mathrm{hBN}$ ceramics were made by Robert Ruh in 1992 for 0, 20, 40, 60, 80, and 100 vol.\% of hexagonal boron nitride. He noticed that there was a large anisotropy of thermal properties [12,13]. Even in the case of the hot-pressing process, a higher concentration of hBN will increase the material porosity and decrease the mechanical properties, which was confirmed by $\mathrm{Li}$ et al. They noticed that a $20 \% \mathrm{~h}-\mathrm{BN}$ addition will improve the friction 
coefficient of such composites and simultaneously, there is an increase in the wear coefficient $[10,14-20]$ when $5 \mathrm{wt} \%$ of h-BN in the material is exceeded. They found that in distilled water conditions, the wear behavior of $\mathrm{B}_{4} \mathrm{C} / \mathrm{h}-\mathrm{BN}$ composites against steel is improved. In dry conditions, limiting the addition of h-BN keeps a good tribological performance of about $10 \%$. In the research made by Ruh, there is a lack of composition between 0 and 20 and $40 \mathrm{vol} . \%$, therefore, for the h-BN content, it is possible to keep a balance between the mechanical properties and thermal conductivity. The author of this paper investigated thermally and mechanically boron carbide $2-8 \mathrm{wt} \%$ of h-BN composites, which were hot-pressed with a chromium carbide sintering aid [21]. In the paper, the addition of h-BN did not decrease the thermal properties significantly, but instead, allowed keeping good values of mechanical properties at a similar or slightly higher level to the reference sample. The introduced 2D phase led to a decrease in the friction coefficient and wear rate.

Based on the works by Ruh and previous research made by the authors of this paper, further research in the $\mathrm{B}_{4} \mathrm{C} / \mathrm{h}$-BN system was made and presented. For $0.5,1,2,4,8,16$, and 32 vol.\% of the $\mathrm{h}-\mathrm{BN}$ content the following anisotropic properties were examined in this paper: Linear thermal expansion coefficient, diffusivity, and thermal conductivity. The obtained thermal data were used to discuss an influence of the added 2D phase on the material cut shape quality after the laser ablation process under a CW mode laser processing. The correlation between thermal properties and laser ablation of boron carbide/h-BN composites provides new information crucial for understanding the rapid heat processing of this composite system and gives new data in the literature concerning the material behavior during laser processing.

\section{Preparation and Examination Route}

To manufacture the boron carbide-hexagonal boron nitride composites, the following commercially available powders were used: Boron carbide grade HS nr AB134566 (97\% purity, $2.51 \mathrm{~g} / \mathrm{cm}^{3}$ density, and $0.8 \mu \mathrm{m}$ average grain size) from the H.C. Starck company (Karlsruhe, Germany) and BO-501 (99.9\% purity, $2.25 \mathrm{~g} / \mathrm{cm}^{3}$ density, and 0.3-0.7 $\mu \mathrm{m}$ grain size) from the Atlantic Equipment Engineers company (Bergenfield, USA). No additional sintering agent was used. The powders were mixed together to obtain mixtures containing $0,0.5,1,2,4,8,16,32$ vol. $\%$ of h-BN phase, which fulfilled the gaps in Ruh mixtures' compositions and further investigations.

As the first step, the boron nitride powder was de-agglomerated in an ultrasonic bath in isopropyl alcohol for $4 \mathrm{~h}$. During this step, boron carbide was added and the ultrasonic was used for $2 \mathrm{~h}$ in order to get a uniform powder mixture. Afterwards, the composition sets were homogenized for $20 \mathrm{~h}$ in a laboratory rotational dissolver, modelTD100 (Pendraulik-Teja) (Springe, Germany) with $900 \mathrm{rpm} / \mathrm{min}$. Such prepared mixtures were dried using a magnetic stirrer with a heating up mode. This step took up to $3 \mathrm{~h}$ with $200 \mathrm{rpm} / \mathrm{min}$. The phase compositions were checked by the XRD analysis (PANalitycal X-Ray Diffractor with X-Pert HighScore software) (Almelo, The Netherlands) and morphology by SEM observations (FEI Nova Nano SEM) (Brno, Czech Republic). The morphology examples of the powders are shown in Figures 1 and 2 and the powder compositions are collected in Table 1. After the de-agglomeration of initial powders, as a result of the powder mixtures homogenization step, we observed two B4C-I and B4C-II boron carbide phases and also two h-BN-I and h-BN-II hexagonal boron nitride phases, which showed slightly different lattice parameters. 


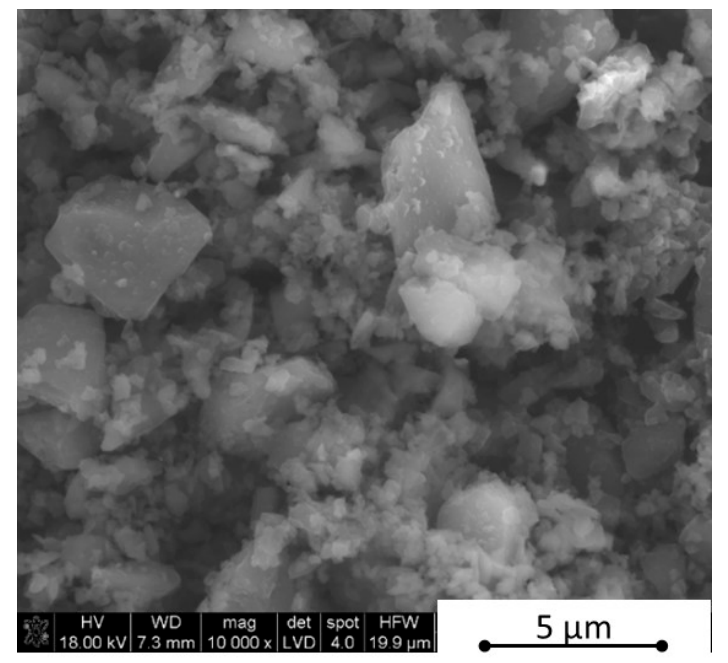

Figure 1. Morphology of commercial boron carbide grade HS of H.C. Starck.

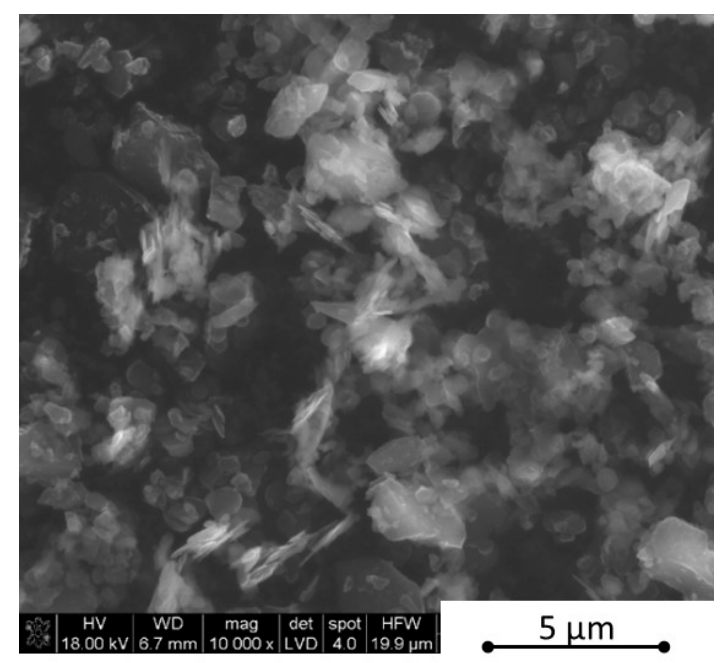

Figure 2. Morphology of the $\mathrm{B}_{4} \mathrm{C}-32$ vol.\% hexagonal boron nitride particles (h-BN) mixture.

Table 1. Phase composition of the $\mathrm{B}_{4} \mathrm{C}-\mathrm{h}-\mathrm{BN}$ mixture after the homogenization step.

\begin{tabular}{cccccc}
\hline \multirow{2}{*}{ Material } & \multicolumn{5}{c}{ Phase Composition of Mixtures (wt \%) } \\
\cline { 2 - 6 } & B $_{4}$ C-I & B $_{4}$ C-II & h-BN-I & h-BN-II & WC \\
\hline$B_{4}$ C & & 0 & 0 & 0 & \\
$\mathrm{~B}_{4}$ C/0.5 h-BN & 47.0 & 50.7 & 1.1 & 1.1 & 0.1 \\
$\mathrm{~B}_{4}$ C/1 h-BN & 46.6 & 49.5 & 1.6 & 2.1 & 0.2 \\
$\mathrm{~B}_{4} \mathrm{C} / 2$ h-BN & 45.1 & 50.3 & 2.0 & 2.4 & 0.2 \\
$\mathrm{~B}_{4} \mathrm{C} / 4$ h- BN & 43.2 & 50.6 & 3.3 & 2.7 & 0.2 \\
$\mathrm{~B}_{4} \mathrm{C} / 8$ h-BN & 46.5 & 44.9 & 5.2 & 3.2 & 0.2 \\
$\mathrm{~B}_{4} \mathrm{C} / 16$ h-BN & 40.9 & 44.1 & 10.2 & 4.6 & 0.2 \\
$\mathrm{~B}_{4} \mathrm{C} / 32$ h-BN & 34.1 & 42.0 & 4.4 & 19.4 & 0.1 \\
\hline
\end{tabular}

The prepared granulated mixtures were hot-pressed using a Thermal Technology LLC HP apparatus (Santa Rosa, CA, USA) at $2150{ }^{\circ} \mathrm{C}$ under $25 \mathrm{MPa}$ for $30 \mathrm{~min}$ in argon flow. The heating rate was $10^{\circ} \mathrm{C} / \mathrm{min}$ and the $25 \mathrm{~mm}$ diameter samples with $8 \mathrm{~mm}$ thickness were obtained.

The apparent density of hot pressed composites was measured by the hydrostatic method. The relative density was calculated and the average XRD phase composition analysis was taken for 
this calculation. Measurements were made for three samples of each composition. Sinters were polished in different material directions using diamond and silica media. The phase composition was investigated by XRD analysis on the sample cross-section and on its surface in perpendicular to the pressing direction. SEM observations were made on the samples' surfaces in parallel and perpendicular direction to the pressing axis, as shown on the example of laser treatment investigations. The element distribution analysis was carried in order to identify phases in the material's microstructure.

Thermal diffusivity and thermal conductivity measurements were carried out using the laser flash analysis method on the Netzsch LFA apparatus (Selb, Germany). The material was investigated at $25^{\circ} \mathrm{C}, 50{ }^{\circ} \mathrm{C}, 100{ }^{\circ} \mathrm{C}, 300{ }^{\circ} \mathrm{C}, 600{ }^{\circ} \mathrm{C}$, and $900{ }^{\circ} \mathrm{C}$ in argon flow. The specific heat was calculated on the base of the thermodynamic data available in the literature [22].

The confocal microscope Olympus Lext OLS4000 (Tokyo, Japan) was used to establish the material surface roughness $\left(\mathrm{R}_{\mathrm{a}}\right)$, which can have an influence on laser beam energy absorption and laser treatment. The examined materials were then taken under laser subtractive processing using the JKLaser 5000 (Rugby, UK) ytterbium doped fiber laser with a $1064 \mathrm{~nm}$ wavelength with a maximum power of $200 \mathrm{~W}$ (JK200FL). The trials were made under the argon flow coming out from the standard cutting head nozzle, where the argon pressure was set to 2 bars. The continuous wave (CW) mode with a $50 \mathrm{~W}$ power laser beam was used to shape the composite material. The laser beam spot was 40 microns. The process speed was set to $3 \mathrm{~mm} / \mathrm{s}$, with a single laser beam pass. The reference and composite material was processed in parallel and perpendicular direction to the material pressing axis of hot-pressing. After the process, the laser treated material was investigated on the cross-section of the laser cut surface by scanning electron microscopy (SEM).

\section{Results and Discussion}

\subsection{Densification and Phase Analysis}

The apparent density results measured by the hydrostatic method is presented in Figure 3. The obtained data shows that dense materials can be obtained only with the addition of up to 8 vol.\% of hexagonal boron nitride, which is higher than the literature data [13]. A further increase of h-BN content led to a decrease in the material density, which results from porous agglomerates of this phase (Figure 4). The density measurement error increases with the h-BN content, which is connected with the h-BN distribution, water adsorption to agglomerates, and a possible absence of h-BN after the HP graphite foil removal. The existence of hexagonal boron nitride agglomerates can lead to a decrease of the material friction coefficient $[21,23]$. Such agglomerates can strongly adsorb a large amount of water from the atmosphere, which was visible on the dilatometric curve changes as a negative jump on the curve. Such material required an additional time in the vacuum chamber in order to remove the adsorbed water before the final CTE analysis, which is described in a further part of this paper.

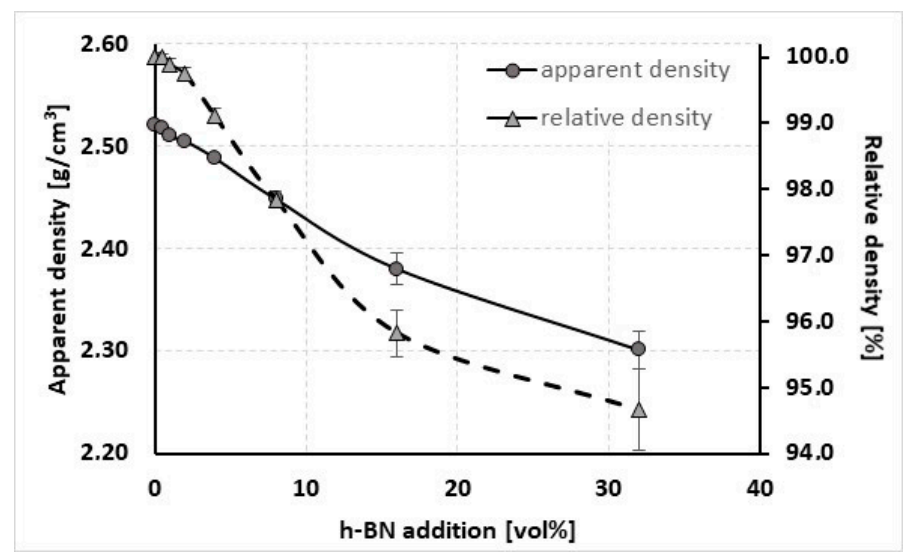

Figure 3. Densification of $\mathrm{B}_{4} \mathrm{C} / \mathrm{h}-\mathrm{BN}$ composites. 


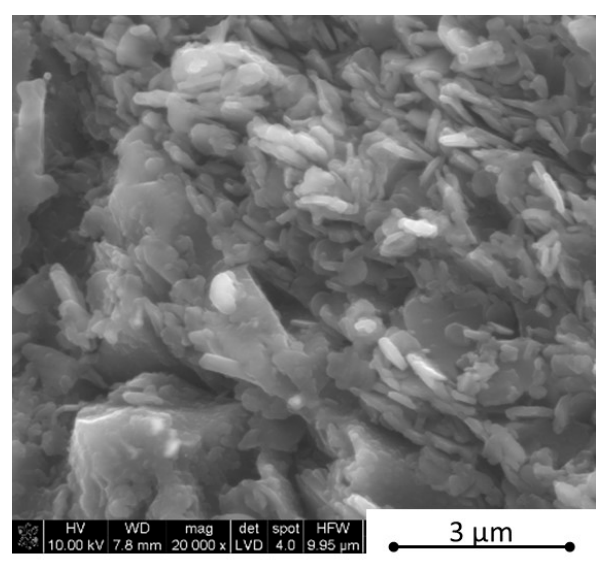

Figure 4. Fracture SEM observation of $\mathrm{B}_{4} \mathrm{C} / 16$ vol. $\%$ h-BN composites.

Due to the uniaxial pressure applied during the hot-pressing process, there should be a difference in the XRD/Rietveld analysis measured in various material directions. XRD peak intensities of selected material phases show various values in different material directions, which have a translation into their content. The result of the phase composition analysis made in perpendicular (in-plane) and parallel (out-of-plane) direction to the pressing axis is presented in Figure 5.

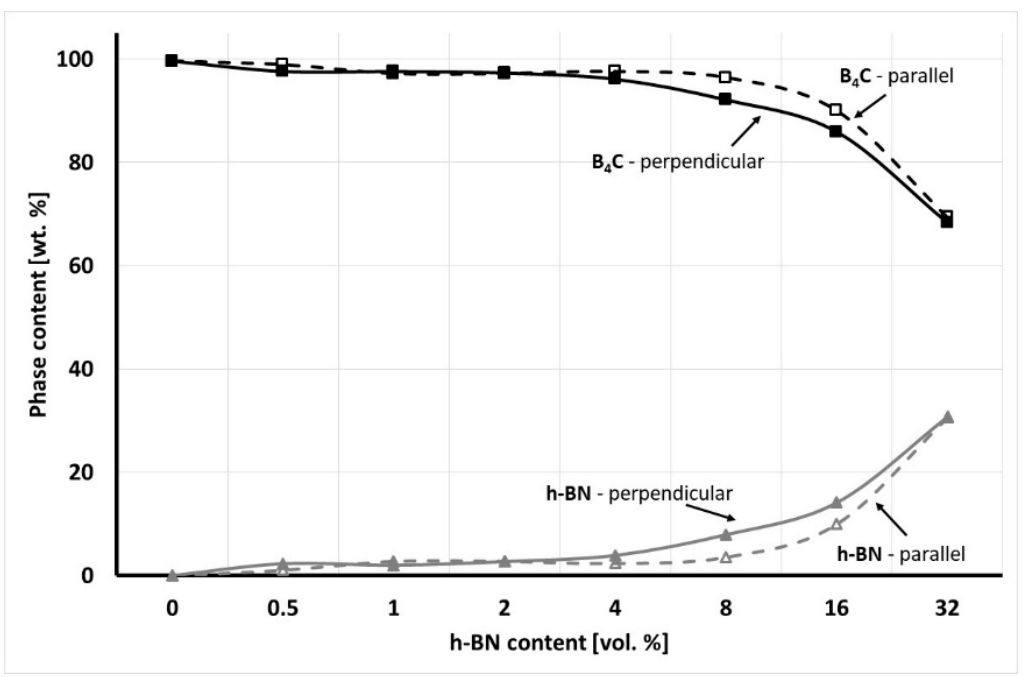

Figure 5. Phase composition analysis versus the $\mathrm{B}_{4} \mathrm{C} / \mathrm{h}-\mathrm{BN}$ composite direction.

The XRD/Rietveld analysis showed that for the hot-pressed material with up to 2 vol.\% there is almost no difference in the composite phase composition in relation to the material direction. The change of the selected phase concentration was noticeable for composites with 8-16 vol.\% of hexagonal boron nitride due to the $2 \mathrm{D}$ phase orientation in the material as a result of applied pressure. For the highest content of h-BN solid lubricant, there was almost no difference due to the high content of even oriented h-BN agglomerates. In the case of a perpendicular direction, $1 \%$ of $\mathrm{B}_{2} \mathrm{O}_{3}$ was present in the samples with $32 \mathrm{vol} \%$ of h-BN. It formed due to the oxidation of h-BN agglomerates. Some of the boron oxide can be present on the initial $\mathrm{B}_{4} \mathrm{C}$ powders grain surface, which cannot be detected due to its low amount. It can happen, for example, during the cutting or polishing process of the sample for XRD analysis. Also small quantity of tungsten borides were found with the used analysis detection level, about $0.4 \%$ in pure material and 1 vol. $\%$ h-BN composite. The $\mathrm{W}_{\mathrm{x}} \mathrm{B}_{\mathrm{y}}$ tungsten boride is a result of the reaction between boron carbide and tungsten carbide impurities. The identification of the phase in the material microstructure was made by the SEM/EDS analysis and presented in Figure 6. The EDS 
analysis was made on the h-BN agglomerate in order to get a good element count. The dark grey colour belongs to boron carbide and the light grey to hexagonal boron nitride.

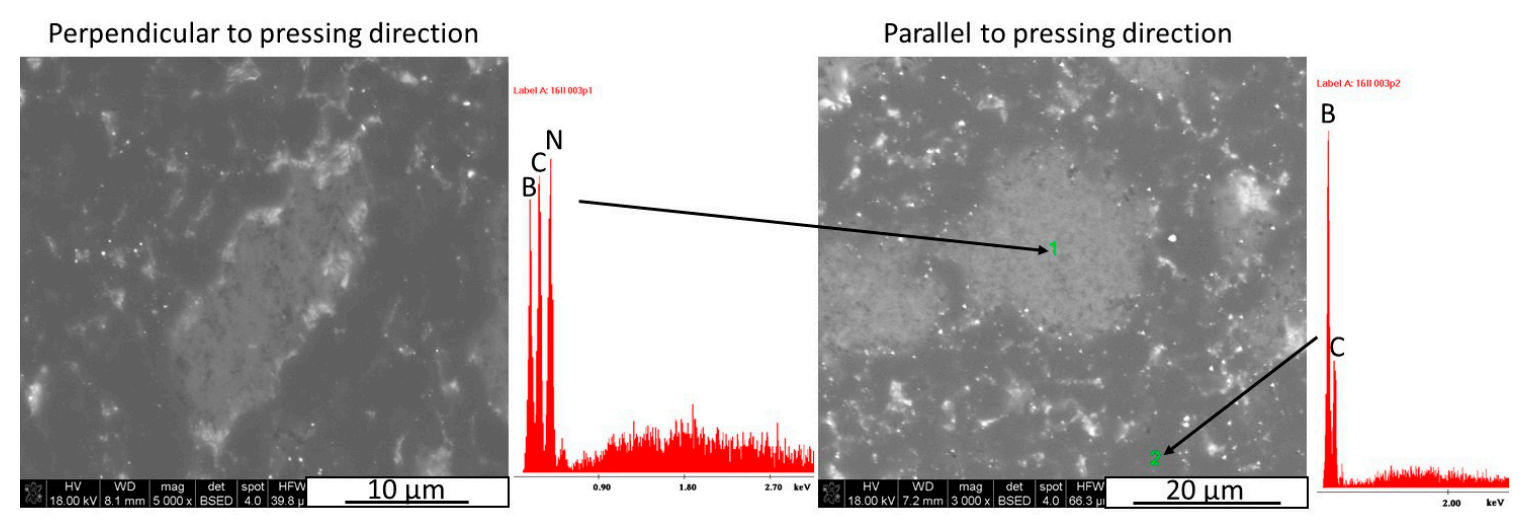

Figure 6. SEM/EDS analysis and phase identification on an example of 16 vol. $\%$ h-BN composite microstructure.

\subsection{Microstructure}

The microstructure observations were made using scanning electron microscopy in parallel and perpendicular direction to the pressing axis of the HP process. The SEM polished surface observations made in parallel direction to the pressing axis are presented in Figures 7 and 8 . The observation of reference material indicates the existence of an additional "white" phase in the microstructure, which was also noticed in the $\mathrm{B}_{4} \mathrm{C} / \mathrm{h}-\mathrm{BN}$ composites and can come from small WC impurities in the initial powders' mixtures. The performed XRD phase composition and EDS element distribution analysis confirmed a formation of tungsten borides as a result of the tungsten carbide reaction with a material matrix during the sintering process. Tungsten carbide was found in up to $0.1 \%$ concentration in the material initial mixtures. The tungsten boride was a contamination in the quantity of up to $0.4 \%$ in sinters. The images in Figures 7 and 8 show an existence of up to $20 \mu \mathrm{m}$ size agglomerates of hexagonal boron nitride for samples in the pressing axis direction. The content of agglomerates increases with the rising concentration of the introduced h-BN to the composites. The fracture images of composites with 16 and 32 vol.\% of h-BN presented in Figures 9 and 10 also confirm some fine h-BN particles/flakes, which are well distributed in the $\mathrm{B}_{4} \mathrm{C}$ matrix and oriented in one direction in the matrix (Figure 10).

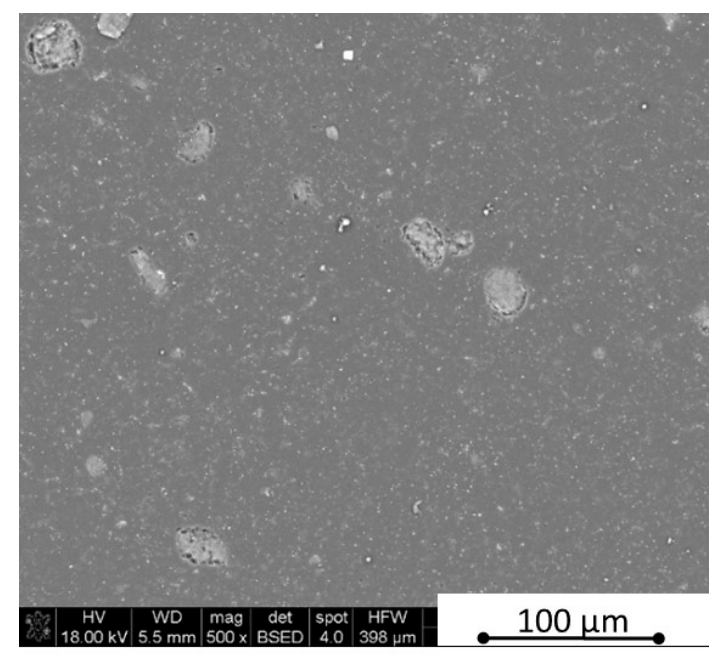

Figure 7. SEM surface observations of composites with 4 vol. $\%$ h-BN (in parallel direction). 


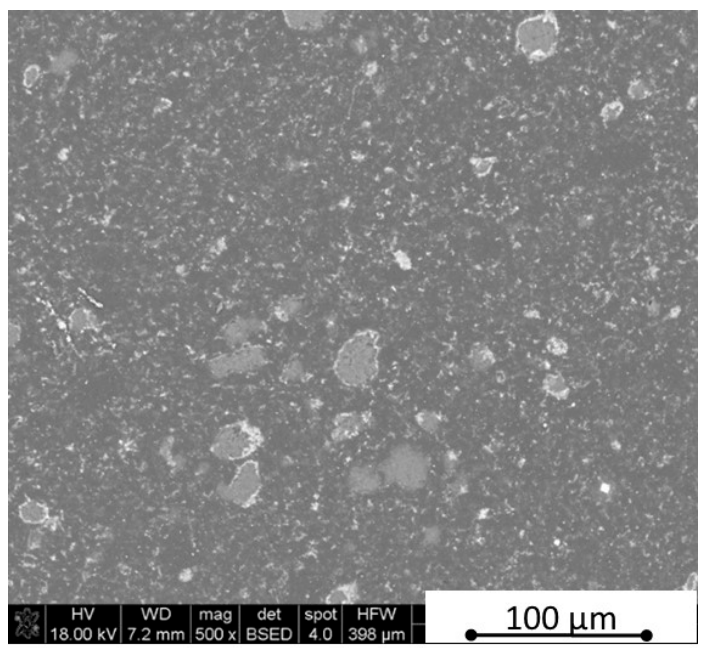

Figure 8. SEM surface observations of composites with 16 vol. $\%$ h-BN (in parallel direction).

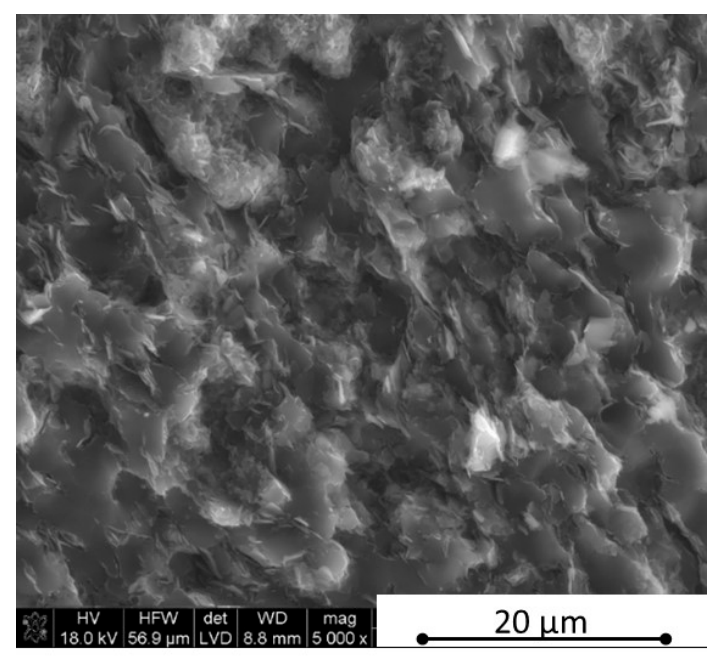

Figure 9. SEM fracture observations of composites with 16 vol. $\%$ h-BN.

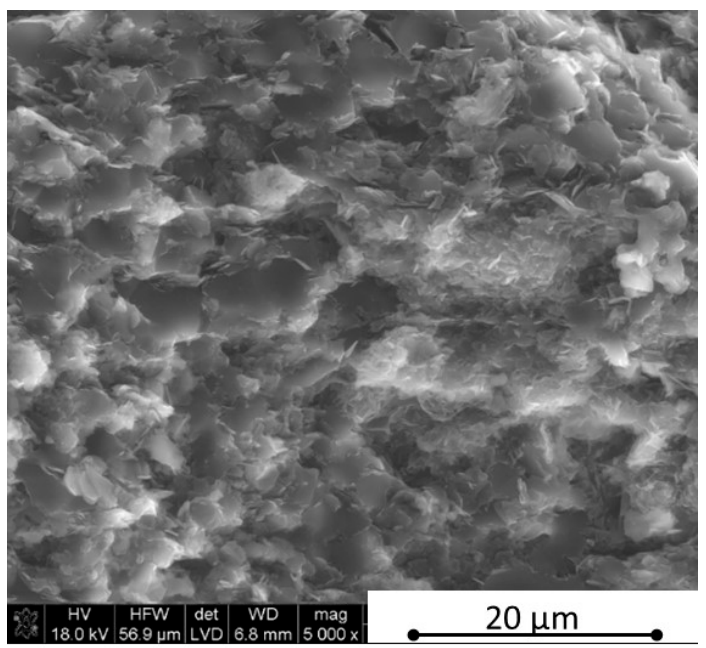

Figure 10. SEM fracture observations of composites with 32 vol. $\%$ h-BN. 
In order to confirm the anisotropic character of manufactured composites, the ultrasonic measurements of longitudinal wave velocity in relation to the material direction were done. The results are shown in Figure 11. The ultrasonic results show the anisotropy of wave velocity reaching $32 \%$ for $32 \mathrm{vol} . \%$ of h-BN. It can also result from the porosity of h-BN agglomerates, where the shape of pores has an important role.

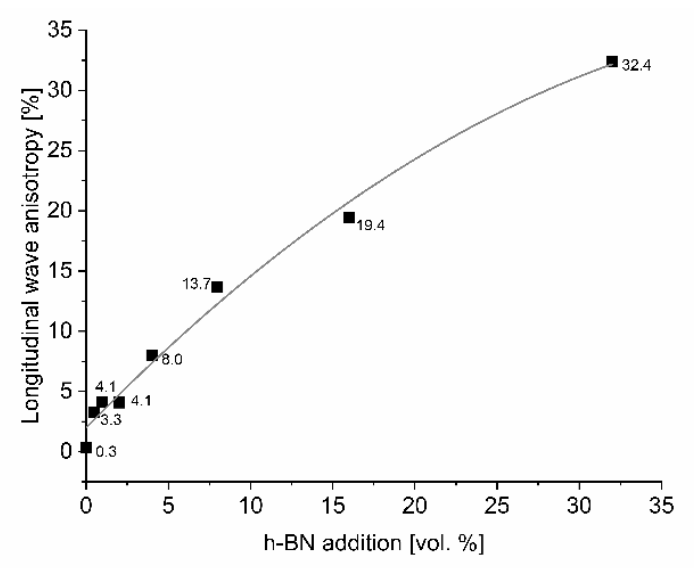

Figure 11. Anisotropy of longitudinal wave velocity of $\mathrm{B}_{4} \mathrm{C} / \mathrm{h}-\mathrm{BN}$ composites.

\subsection{Thermal Properties and Thermal Stability}

The determination of thermal conductivity by the direct thermal diffusivity analysis on a LFA apparatus cannot be made without specific heat data, linear material dimension changes, and density changes by dilatometry. The calculated specific heat on the base of thermodynamic data [22] and the calculated density on the base of dilatometric measurements are shown in Figures 12 and 13 . The density changes were calculated on the base of the thermal expansion coefficient measured in various material directions, which is presented in Figure 14 for the technical linear CTE and in Figure 15 for the physical linear CTE. The conducted measurements and calculations showed a slight decrease of material density with the increased temperature, which has a negligible influence on the thermal conductivity analysis. For future purposes, the mathematical functions were fitted to the experimental data and collected in Table 2. Figure 14 shows a similar behavior of density changes for all of the manufactured polycrystalline materials.

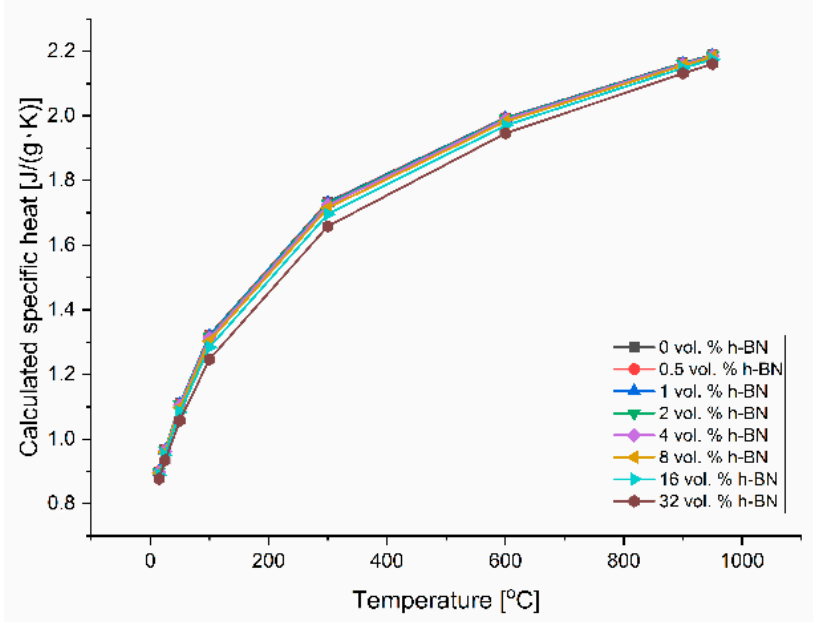

Figure 12. Calculated specific heat versus temperature on the base of NIST database [22]. 


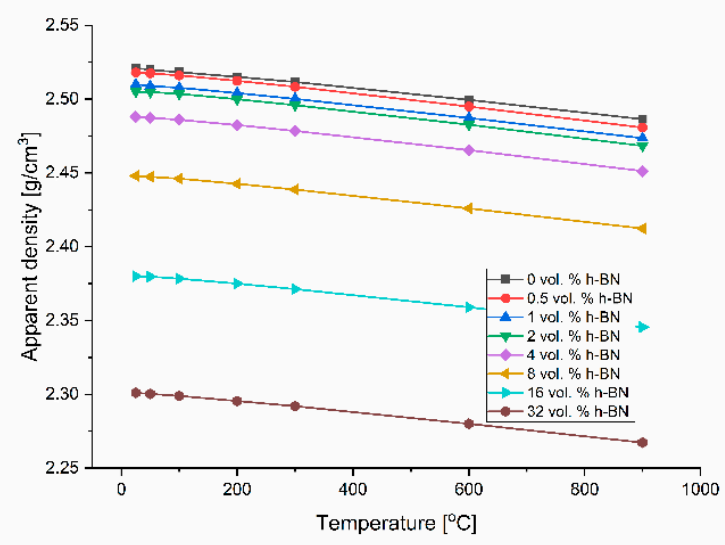

Figure 13. Experimental density changes versus temperature.

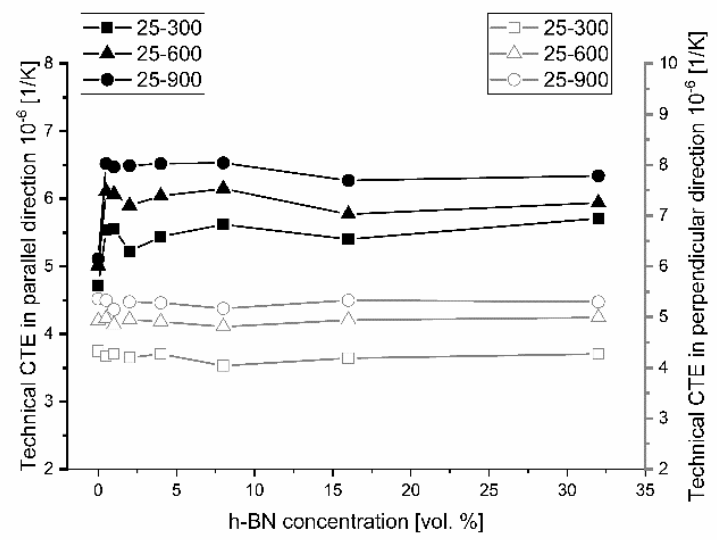

Figure 14. Material technical thermal expansion coefficient versus material direction. Empty marks are for the perpendicular direction to the pressing axis (in two-dimensional (2D) plane), and filled marks are for the pressing direction (out-of-plane).

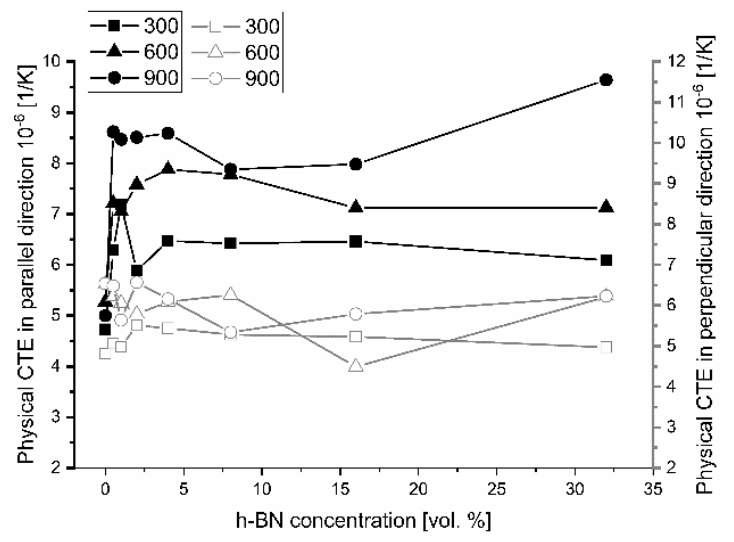

Figure 15. Material physical thermal expansion coefficient versus material direction. Empty marks are for the perpendicular direction to the pressing axis (in 2D plane), and filled marks are for the pressing direction (out-of-plane). 
Table 2. Mathematical function of density changes fitted to the experimental data (T-temperature $\left.\left({ }^{\circ} \mathrm{C}\right)\right)$.

\begin{tabular}{|c|c|c|}
\hline vol. $\%$ of h-BN & $\begin{array}{l}\text { Mathematical Function of Density } \\
\text { Changes }\left(\mathrm{g} / \mathrm{cm}^{3}\right)\end{array}$ & Fitting \\
\hline 0 & $\mathrm{y}=-9 \times 10^{-9} \mathrm{~T}^{2}-3 \times 10^{-5} \mathrm{~T}+2.5216$ & $R^{2}=0.9998$ \\
\hline 0.5 & $\mathrm{y}=-1 \times 10^{-8} \mathrm{~T}^{2}-3 \times 10^{-5} \mathrm{~T}+2.5192$ & $R^{2}=0.9996$ \\
\hline 1 & $\mathrm{y}=-9 \times 10^{-9} \mathrm{~T}^{2}-3 \times 10^{-5} \mathrm{~T}+2.5109$ & $R^{2}=0.9997$ \\
\hline 2 & $\mathrm{y}=-1 \times 10^{-8} \mathrm{~T}^{2}-3 \times 10^{-5} \mathrm{~T}+2.5064$ & $R^{2}=0.9993$ \\
\hline 4 & $\mathrm{y}=-1 \times 10^{-8} \mathrm{~T}^{2}-3 \times 10^{-5} \mathrm{~T}+2.4891$ & $R^{2}=0.9998$ \\
\hline 8 & $\mathrm{y}=-1 \times 10^{-8} \mathrm{~T}^{2}-3 \times 10^{-5} \mathrm{~T}+2.4491$ & $R^{2}=0.9996$ \\
\hline 16 & $\mathrm{y}=-1 \times 10^{-8} \mathrm{~T}^{2}-3 \times 10^{-5} \mathrm{~T}+2.3812$ & $R^{2}=0.9996$ \\
\hline 32 & $\mathrm{y}=-8 \times 10^{-9} \mathrm{~T}^{2}-3 \times 10^{-5} \mathrm{~T}+2.3020$ & $R^{2}=0.9999$ \\
\hline
\end{tabular}

The results of thermal expansion coefficient shown in Figures 14 and 15 indicate high anisotropy material linear changes versus material direction. A sudden increase of the technical and physical CTE value in the perpendicular direction begins for 0.5 vol. $\%$ of the h-BN content in the composite. A higher addition of h-BN does not significantly change the technical CTE. For the parallel direction to the pressing axis, it stays on the level of $5.4 \times 10^{-6} 1 / \mathrm{K}$ for $25-300^{\circ} \mathrm{C}$ measurement range, $5.9 \times 10^{-6} 1 / \mathrm{K}$ for $25-600{ }^{\circ} \mathrm{C}$ measurement range, and $6.3 \times 10^{-6} 1 / \mathrm{K}$ for $25-900{ }^{\circ} \mathrm{C}$ measurement range. For the perpendicular direction to the pressing axis, it is as follows: $4.2 \times 10^{-6} 1 / \mathrm{K}$ for $25-300^{\circ} \mathrm{C}$ measurement range, $4.9 \times 10^{-6} 1 / \mathrm{K}$ for $25-600^{\circ} \mathrm{C}$ measurement range, and $5.3 \times 10^{-6} 1 / \mathrm{K}$ for $25-900{ }^{\circ} \mathrm{C}$ measurement range. The dilatometric analysis showed the material linear changes fluctuation in the case of physical CTE, which varied in relation to the h-BN content and especially the high temperatures visible for 32 vol. $\%$ h-BN at $900^{\circ} \mathrm{C}$. The calculated data of the technical and physical CTE anisotropy are illustrated in Figures 16 and 17. For high temperatures, the physical CTE anisotropy stays on the level of 50\%. For lower temperatures, it is mostly between $20 \%$ and $30 \%$ (Figure 17). For the technical CTE, all the measured temperature ranges are between $20 \%$ and $30 \%$ (Figure 16 ).

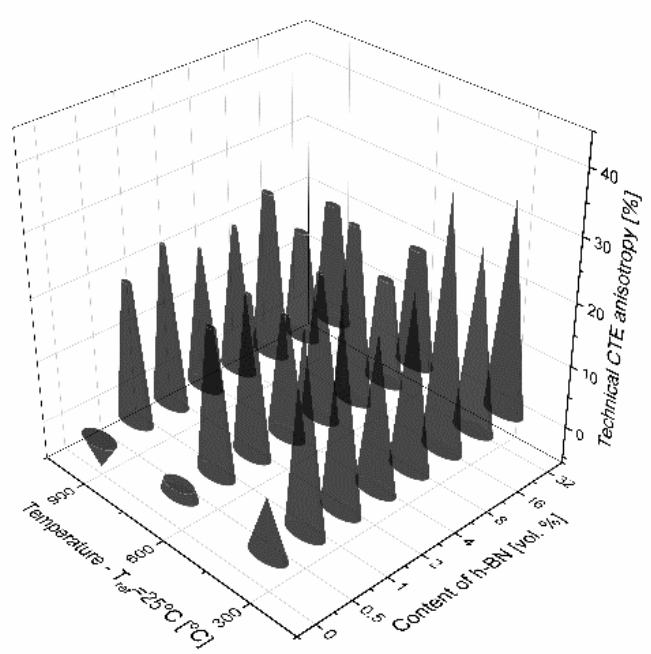

Figure 16. Anisotropy of the technical thermal expansion coefficient. 


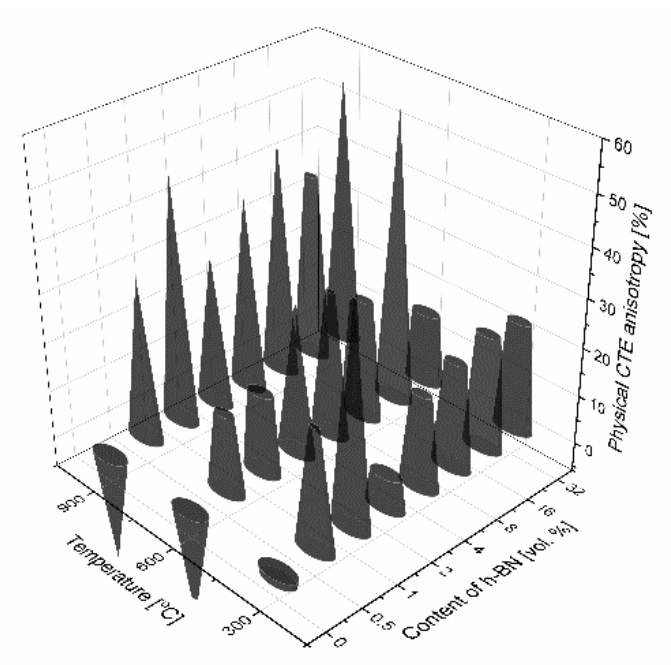

Figure 17. Anisotropy of the physical thermal expansion coefficient.

In the literature, there is no excessive information concerning the influence of $0-32 \mathrm{vol} . \% \mathrm{~h}-\mathrm{BN}$ and the applied pressure of the hot-pressing process on the anisotropy of heat transport versus temperature in the boron carbide composite matrix. This is why the examples of thermal diffusivity data measured as a function of temperature and material direction are presented in Figures 18 and 19. For lower contents of h-BN, there is a slight increase of heat transfer due to the high material densification above $99 \%$, low content of flat defects (interphase boundary), and second 2D high conductive phase and low material anisotropy (Figure 11). A similar situation occurs when using a low quantity of graphene powder (GNP), where a small amount of 2D particles leads to an increase of thermal conductivity [23]. In the case of parallel direction to the pressing axis (Figure 18), at lower temperatures diffusivity decreases with the h-BN addition higher than 4 vol.\%. It is caused by a higher material porosity connected mostly with h-BN agglomerates, increasing the concentration of flat defects (fractures in Figures 9 and 10) and orientation of 2D particles. The thermal conductivity of a platelet shaped h-BN is above $200 \mathrm{~W} /(\mathrm{m} \cdot \mathrm{K})$ in the plane direction and around $2 \mathrm{~W} /(\mathrm{m} \cdot \mathrm{K})$ through the plane direction [24]. The authors of [24] confirmed that in the plane orientation of $\mathrm{h}-\mathrm{BN}$, larger thermal properties than in the perpendicular direction make the $2 \mathrm{D}$ particle plane. They also showed that very small particles and large agglomerates tend to orient less, therefore, it can also have an influence on thermal properties, which is its value in our case in perpendicular direction to the pressing axis. The scattering of phonon at boundaries of the studied samples will cause the heat transfer to decrease mainly in perpendicular direction to the pressing axis due to the material anisotropy. For higher temperatures $\left(900^{\circ} \mathrm{C}\right)$ all curves reach values between 2.3 and $2.6 \mathrm{~mm}^{2} / \mathrm{s}$. The results of thermal diffusivity measured in perpendicular direction show higher values for the higher h-BN content in a whole range of temperatures. This parameter decreased with the temperature more slightly than in the parallel direction. At $900{ }^{\circ} \mathrm{C}$, increasing the h-BN content thermal diffusivity changes from 2.4 to $3.8 \mathrm{~mm}^{2} / \mathrm{s}$ is visible in Figure 19 . 


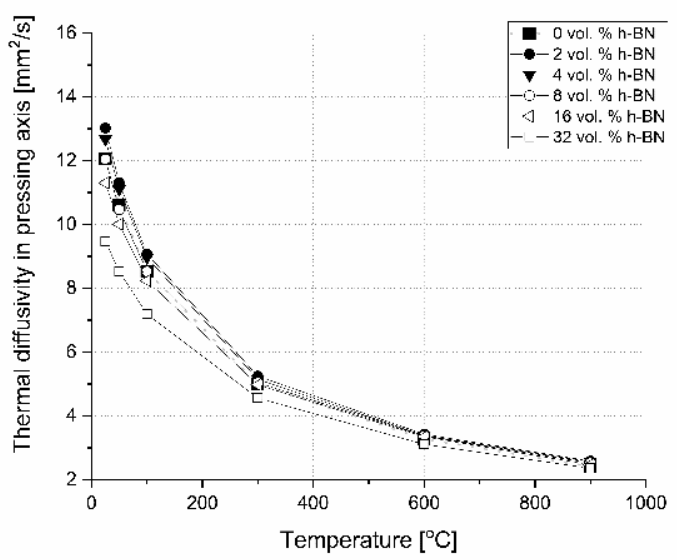

Figure 18. Thermal diffusivity versus temperature and h-BN content in the pressing direction.

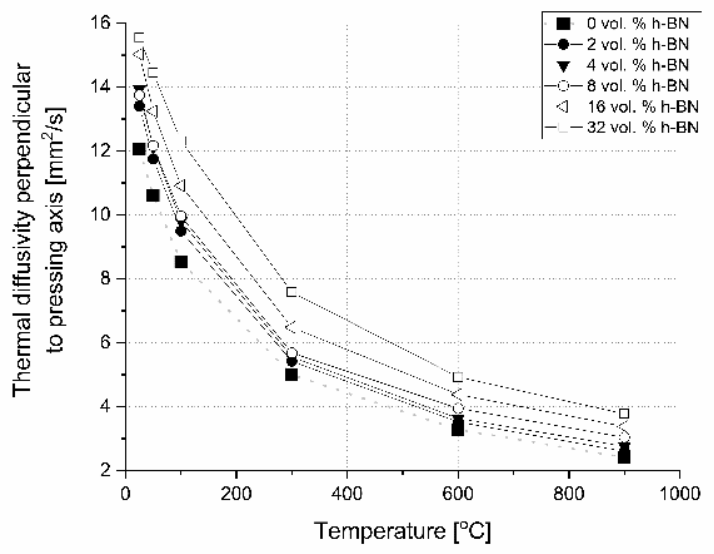

Figure 19. Thermal diffusivity versus temperature and h-BN content perpendicularly to the pressing direction.

Concerning the pure nonstoichiometric boron carbide, the electronic transport causing polarons and phonon a play role in thermal conductivity and it was explained in NASA papers [25]. In our paper, we describe the $\mathrm{B}_{4} \mathrm{C} / \mathrm{h}-\mathrm{BN}$ composites thermal conductivity calculated on the base of thermal diffusivity, material density, and specific heat changes. Results of this parameter are illustrated in Figure 20 for the parallel measurement direction to the pressing axis (out-of-plane) and in Figure 21 for the perpendicular measurement direction to the pressing axis (in-plane). Due to specific heat in most of the manufactured composites, thermal conductivity increases slightly in the $25-50{ }^{\circ} \mathrm{C}$ range. The increase of thermal conductivity is caused by high conductive $2 \mathrm{D}$ particles, high material densification, and lower 2D agglomerates content. For higher temperatures, there is a decrease of this property possibly due to phonon-phonon scattering (Figures 20 and 21). The addition of a low amount of h-BN allows obtaining slightly about $7 \%$ higher thermal properties in parallel direction to the pressing axis than for the reference sample of $29.6 \mathrm{~W} /(\mathrm{m} \cdot \mathrm{K})$. In the pressing direction, the higher decrease in thermal properties of this material with a temperature rise is also visible for composites with a higher h-BN content above 8 vol.\%, which is marked by empty chart markers (Figure 20). Here, we have additional phonon scattering at boundaries and higher material porosity, which influence the lower heat transfer especially in the pressing direction. The thermal conductivity at $900{ }^{\circ} \mathrm{C}$ in this material direction is in the level of $11.3-13.8 \mathrm{~W} /(\mathrm{m} \cdot \mathrm{K})$ - the highest value is for $2 \mathrm{vol} . \% \mathrm{~h}$-BN addition and the lowest for 32 vol.\% of this phase. Due to the high material densities (Figure 3), in the case of low h-BN concentrations the decrease of thermal properties in low temperatures can be explained 
by the finer microstructure following the $\mathrm{h}-\mathrm{BN}$ addition, therefore, increasing flat defects (usually 2D particles are limiting the grain growth of matrix during the hot-pressing process). The fine material microstructure is presented in Figures 9 and 10. For higher temperatures, the phonon-phonon scattering and phase orientation mostly influence thermal conductivity. In thermal conductivity, the thermal barrier existing on the $\mathrm{B}_{4} \mathrm{C} / \mathrm{h}-\mathrm{BN}$ interface is very important, which was noticed by Ruh [13]. He stated that the mismatch in the elastic modulus of $\mathrm{B}_{4} \mathrm{C}$ and $\mathrm{h}$-BN phases will cause phonon scattering. He also discussed that the microcracking or interracial adhesion can form a thermal barrier-which is in our case during the 2D particle orientation. Moreover, he added that Niihara discussed a possible thermal barrier on an example of $\mathrm{Si}_{3} \mathrm{~N}_{4}$-BN composites. In our case, the higher amount of h-BN gives significantly lower thermal properties values, which is not only connected with an h-BN single particles/agglomerates orientation, but also higher porosity (lower density-Figure 3) existing in h-BN agglomerates. In the case of perpendicular direction, thermal conductivity values increase with the addition of a h-BN solid lubricant, which is visible for low temperatures up to $100{ }^{\circ} \mathrm{C}$ (Figure 21), but for higher temperatures they stay much higher than the reference sample. It can be explained by the h-BN particle orientation in perpendicular direction to the pressing axis (also confirmed by ultrasonic measurements) and agglomerates that the shape is elongated in this direction. The literature says that removing agglomerates or limiting their size can give a higher anisotropy, resulting in larger values of thermal properties in the 2D particle orientation [24], which can be a task for future research. In this direction, thermal conductivities at $900{ }^{\circ} \mathrm{C}$ stay above $13 \mathrm{~W} /(\mathrm{m} \mathrm{K})$ reaching $18.3 \mathrm{~W} /(\mathrm{m} \cdot \mathrm{K})$ for the case of the highest $\mathrm{h}-\mathrm{BN}$ concentration. The decrease of thermal properties in perpendicular direction in the temperature function is less aggressive than in the parallel case. For a future investigation, the fitted mathematical functions of thermal conductivity are given in Table 3.

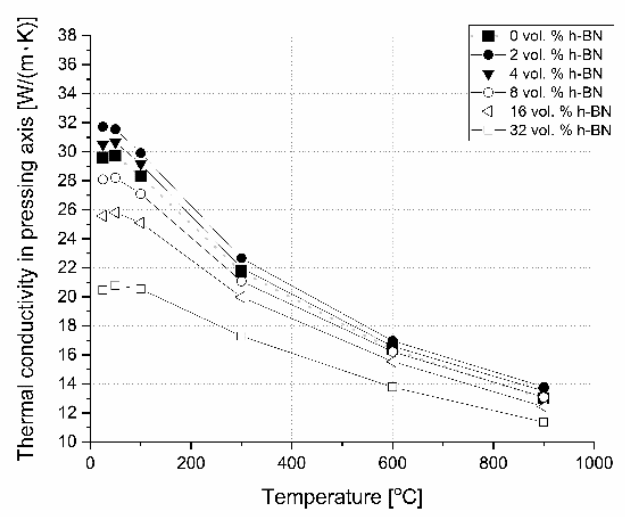

Figure 20. Thermal conductivity versus temperature and h-BN content in pressing direction.

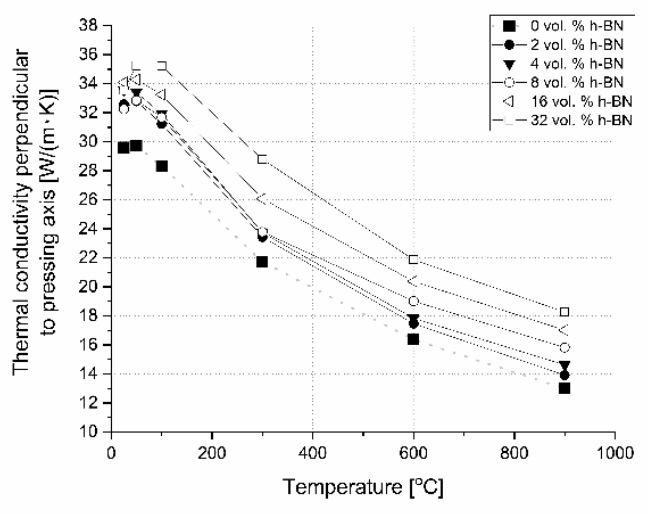

Figure 21. Thermal conductivity versus temperature and h-BN content perpendicularly to the pressing direction. 
Table 3. Mathematical function of heat transfer values changes fitted to the experimental data.

\begin{tabular}{|c|c|c|c|c|c|c|c|}
\hline \multirow{2}{*}{$\begin{array}{l}\text { vol.\% } \\
\text { h-BN }\end{array}$} & \multirow[t]{2}{*}{ Direction } & \multicolumn{2}{|c|}{$\begin{array}{c}\text { Diffusivity } \mathrm{mm}^{2} / \mathrm{s} \\
A=-A \ln (T)+B\end{array}$} & \multicolumn{4}{|c|}{$\begin{array}{c}\text { Conductivity W/(m K) } \\
\lambda=\mathrm{AT}^{3}+\mathrm{BT}^{2}+\mathrm{CT}+\mathrm{D}\end{array}$} \\
\hline & & A & B & A & B & $\mathrm{C}$ & D \\
\hline 0 & Parallel & 2.801 & 21.282 & $-1 \times 10^{-9}$ & $2 \times 10^{-5}$ & -0.0351 & 31.093 \\
\hline \multirow[b]{2}{*}{2} & Parallel & 3.029 & 22.911 & $-5 \times 10^{-9}$ & $3 \times 10^{-5}$ & -0.0417 & 33.295 \\
\hline & Perpendicular & 3.149 & 23.780 & $-1 \times 10^{-9}$ & $2 \times 10^{-5}$ & -0.0409 & 34.366 \\
\hline \multirow{2}{*}{4} & Parallel & 2.950 & 22.372 & $-2 \times 10^{-9}$ & $2 \times 10^{-5}$ & -0.0387 & 32.156 \\
\hline & Perpendicular & 3.257 & 24.599 & $-4 \times 10^{-9}$ & $3 \times 10^{-5}$ & -0.0449 & 35.327 \\
\hline \multirow{2}{*}{8} & Parallel & 2.750 & 21.039 & $2 \times 10^{-10}$ & $1 \times 10^{-5}$ & -0.0305 & 29.424 \\
\hline & Perpendicular & 3.140 & 24.124 & $-5 \times 10^{-9}$ & $3 \times 10^{-5}$ & -0.0397 & 34.282 \\
\hline \multirow{2}{*}{16} & Parallel & 2.559 & 19.794 & $5 \times 10^{-9}$ & $2 \times 10^{-6}$ & -0.0221 & 26.678 \\
\hline & Perpendicular & 3.395 & 26.243 & $6 \times 10^{-9}$ & $9 \times 10^{-6}$ & -0.0331 & 35.631 \\
\hline \multirow{2}{*}{32} & Parallel & 2.066 & 16.418 & $1 \times 10^{-8}$ & $-1 \times 10^{-5}$ & -0.0086 & 21.088 \\
\hline & Perpendicular & 3.501 & 27.643 & $5 \times 10^{-8}$ & $6 \times 10^{-5}$ & -0.0038 & 34.929 \\
\hline
\end{tabular}

The material properties can change as a result of: Oxygen contamination in argon protective gas, high temperature, long material treatment, and laser beam processing during the LFA measurement. This is the reason why two extreme sample compositions of the reference boron carbide polycrystalline material and one with 32 vol.\% h-BN were taken under thermal conductivity measurements during heating and cooling steps. Results of this cyclic experiment are presented in Figures 22 and 23. The obtained results show that there is almost no influence of laser processing, temperature, and gas purity on the thermal properties of boron carbide based polycrystalline materials with and without the $\mathrm{h}$-BN dispersed phase. The material is thermally stable in a protective atmosphere.

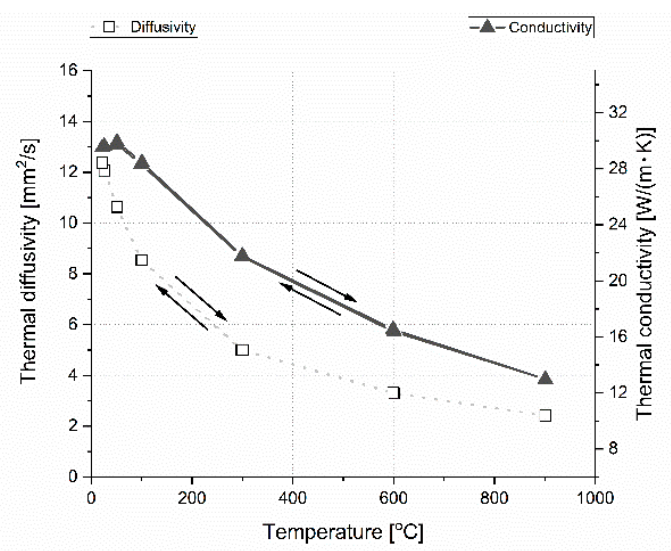

Figure 22. Stability investigation of thermal diffusivity and conductivity of $\mathrm{B}_{4} \mathrm{C}$ reference material in parallel direction. The arrows indicate the direction of heating and cooling during the measurement. 


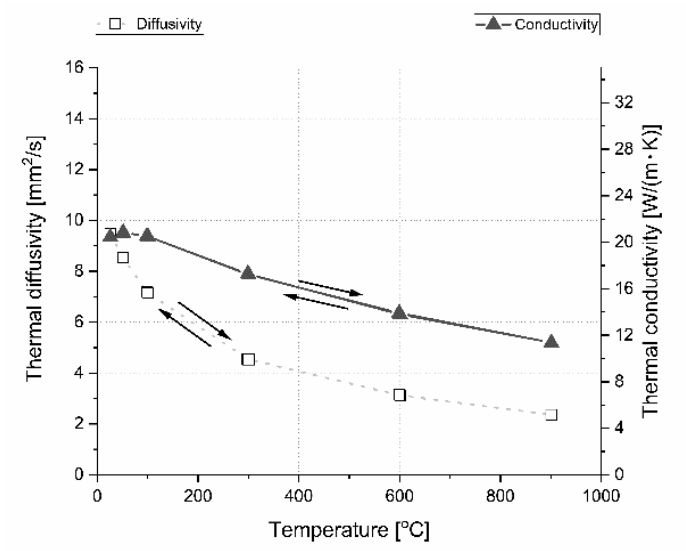

Figure 23. Stability investigation of thermal diffusivity and conductivity of $\mathrm{B}_{4} \mathrm{C}$ with 32 vol.\% h-BN in parallel direction. The arrows indicate the direction of heating and cooling during the measurement.

For the onset of laser processing description, the heat transfer properties at room temperature are very important (Figure 24). During the process, material properties at higher temperatures become much more interesting. The change of thermal diffusivity and conductivity at $900{ }^{\circ} \mathrm{C}$ is illustrated in Figure 25, which is the approximate temperature that stays around the laser-treated place for a short time after the interaction between the laser and sample.

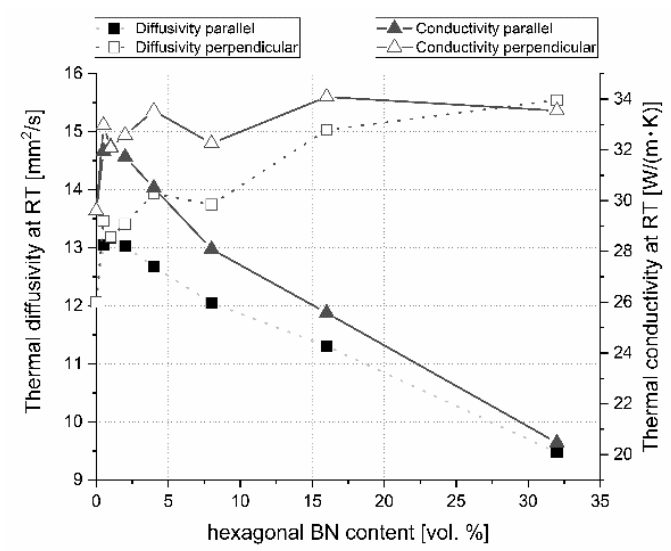

Figure 24. Thermal diffusivity and conductivity changes versus material direction and boron nitride content at room temperature (RT).

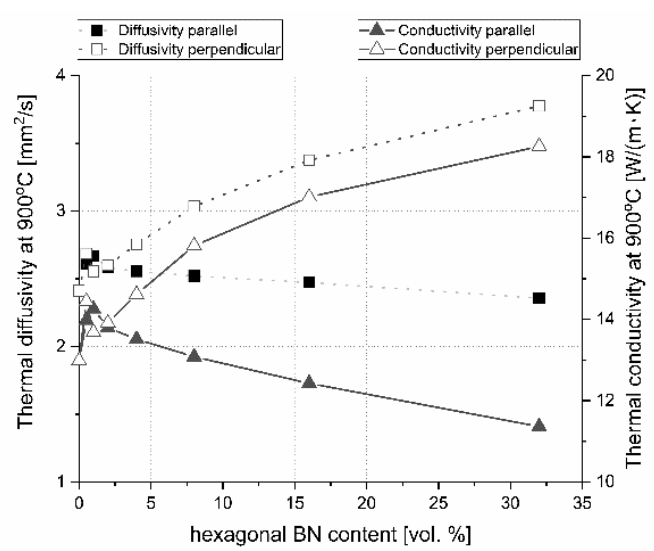

Figure 25. Thermal diffusivity and conductivity changes versus material direction and boron nitride content at $900{ }^{\circ} \mathrm{C}$. 
The addition of hexagonal boron nitride will lead to an anisotropy of the thermal conductivity/diffusivity as a result of the dispersed particles and pores orientation in the material microstructure. For room temperature (RT) conditions in the pressing axis direction, an increase of h-BN particles will cause a strong decrease in thermal properties especially in the case of its higher h-BN content. A different situation occurs in the perpendicular direction where the heat transfer is faster. A similar situation can be met in high temperatures. There is a large thermal properties anisotropy at low and high temperature which increased with the higher h-BN content in the composites, as clearly visible in Figures 24 and 25. This situation can have an influence on the material treatment, which is presented in the next part of this paper.

\subsection{Subtractive Laser Processing}

There is some information in the literature about ceramic laser machining mostly in a pulse mode and also in a continuous wave mode. The available example of an $8 \mathrm{~mm}$ thick ceramic tails laser cutting was shown by Black and Chua [26] in 1997. Their results confirmed that the pulse and continuous (CW) wave condition needs the multi-pass process, while in the case of $\mathrm{CW}$, it was 60 passes, which is around $150 \mu \mathrm{m}$ depth of a single cut. They were working with both the laser mode and $\mathrm{CO}_{2}$ laser. For alumina it is 200 to $400 \mu \mathrm{m}$, and for a good quality silicon carbide it is up to $300 \mu \mathrm{m}$ in the laser pulse mode using the Yb:KGW laser (city, country) [27]. The laser ceramic treatment depth was show also in publication [28]. However, there is no information concerning the laser cutting of anisotropic ceramic composites. In this study, the laser treated materials were taken into the laser cutting process using a standard cutting laser head, argon flow, and continuous wave working mode. The process was done and analyzed in two different material directions and for the material roughness $\left(R_{a}\right)$ it was much lower and much higher than the wave length. For grinded materials with $R_{a}$ around $2.69 \mu \mathrm{m}$, the observations are shown in Figures 26-31 and for polished composites with $R_{a}$ around $0.56 \mu \mathrm{m}$, the observations are presented in Figures 32-37. A too low material roughness will lead to a light reflection. In this case, it gives a slightly better material treatment than in the case of a minimum of 2 times higher roughness towards the used laser wave length. In the case of a too high material $\left(\mathrm{R}_{\mathrm{a}}\right)$, some energy absorbed by surface unevenness tends to generate some heat that is not involved in the material processing. Therefore, a too rough surface makes the effect of laser processing slightly lower in the perpendicular material direction than in the case of polished surface for a high amount of h-BN. For low concentrations of introduced hexagonal boron nitrides, there are visible cracks (Figures 28, 29, 31 and 35 ) or materials which are almost destroyed (Figures 27 and 34). Lots of cracks appear in the remelted areas (Figure 28). Cracks and material destruction during laser processing can appear as an effect of a large CTE difference between boron carbide and hexagonal boron nitride single phases (Figures 14-17). From the authors' experience, similar cracks can possibly appear as an effect of h-BN decomposition and released nitrogen overpressure or in the case of residual water adsorbed in h-BN agglomerates. 


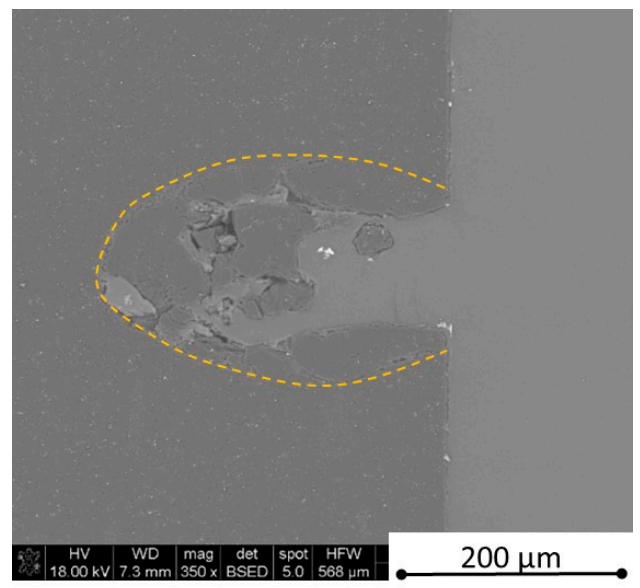

Figure 26. SEM observations of a $50 \mathrm{~W}$ laser processed $\mathrm{B}_{4} \mathrm{C}$ reference sample (high surface roughness).

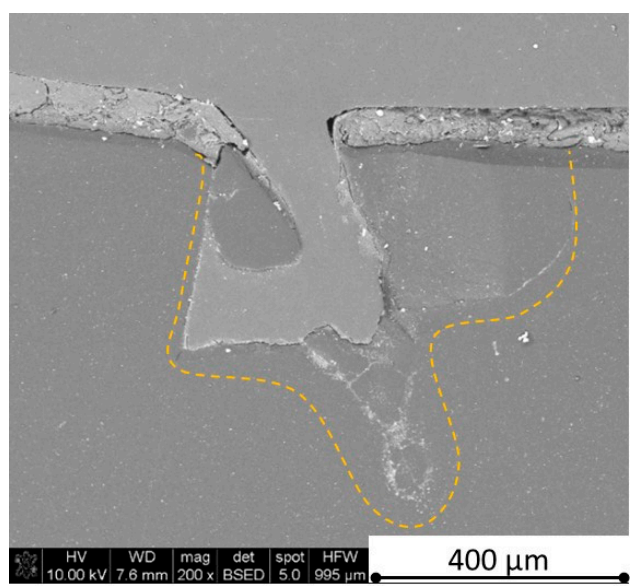

Figure 27. SEM observations of a $50 \mathrm{~W}$ laser processed $\mathrm{B}_{4} \mathrm{C}$ reference sample (high surface roughness).

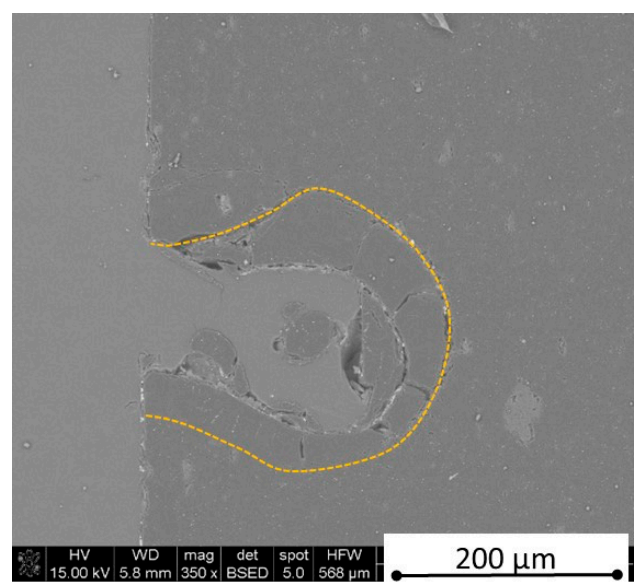

Figure 28. SEM observations of a $50 \mathrm{~W}$ laser processed $\mathrm{B}_{4} \mathrm{C}-4$ vol. $\% \mathrm{~h}-\mathrm{BN}$ in pressing direction (high surface roughness). 


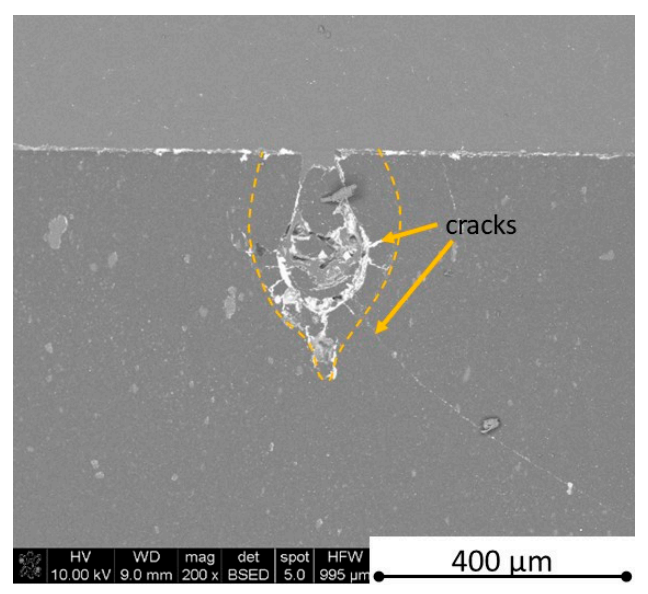

Figure 29. SEM observations of a $50 \mathrm{~W}$ laser processed $\mathrm{B}_{4} \mathrm{C}-4$ vol. $\% \mathrm{~h}-\mathrm{BN}$ in perpendicular direction (high surface roughness).

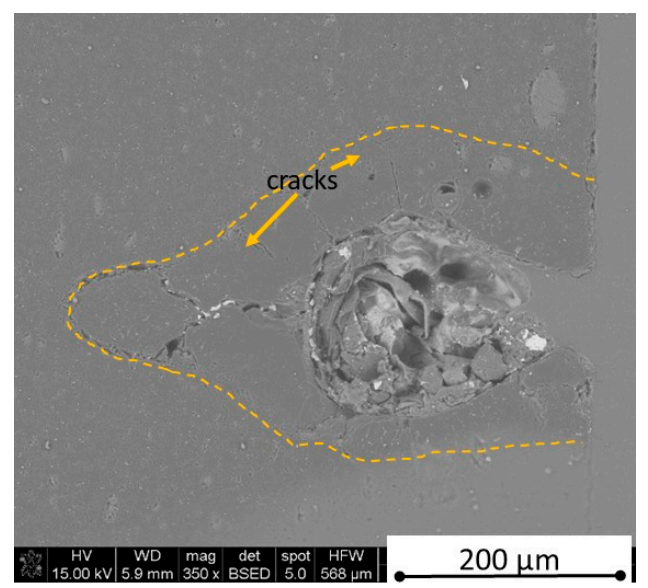

Figure 30. SEM observations of a $50 \mathrm{~W}$ laser processed $\mathrm{B}_{4} \mathrm{C}-8$ vol. $\% \mathrm{~h}-\mathrm{BN}$ in pressing direction (high surface roughness).

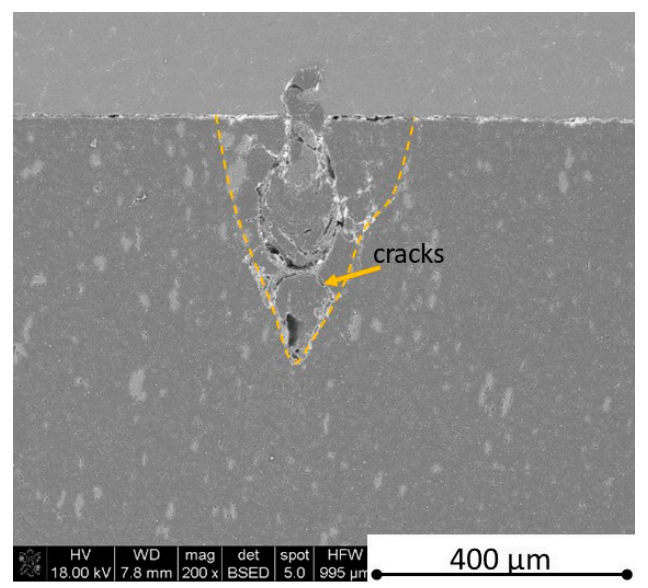

Figure 31. SEM observations of a $50 \mathrm{~W}$ laser processed $\mathrm{B}_{4} \mathrm{C}-8 \mathrm{vol} . \% \mathrm{~h}-\mathrm{BN}$ in perpendicular direction (high surface roughness). 


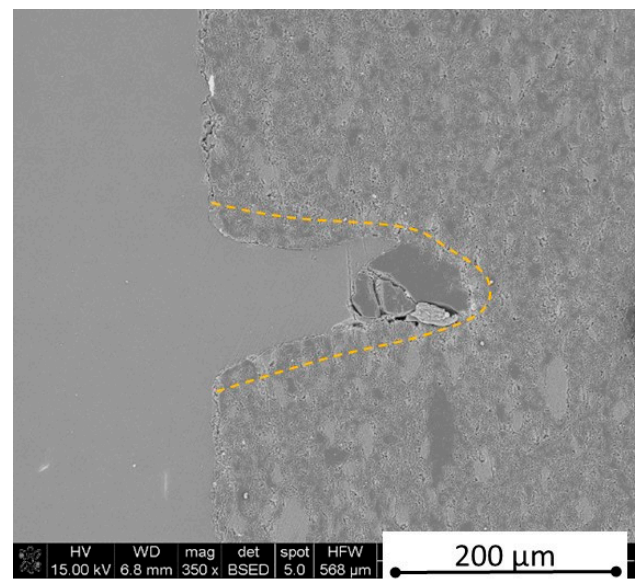

Figure 32. SEM observations of a $50 \mathrm{~W}$ laser processed $\mathrm{B}_{4} \mathrm{C}-32 \mathrm{vol} . \% \mathrm{~h}-\mathrm{BN}$ in pressing direction (high surface roughness).

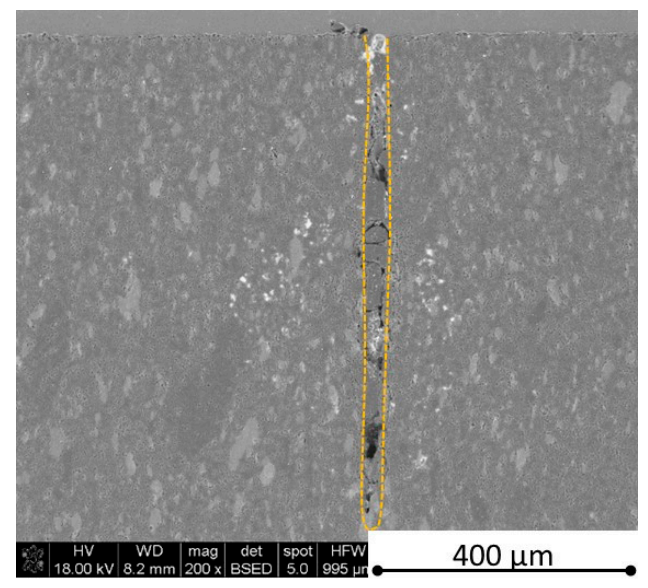

Figure 33. SEM observations of a $50 \mathrm{~W}$ laser processed $\mathrm{B}_{4} \mathrm{C}-32 \mathrm{vol} . \% \mathrm{~h}-\mathrm{BN}$ in perpendicular direction (high surface roughness).

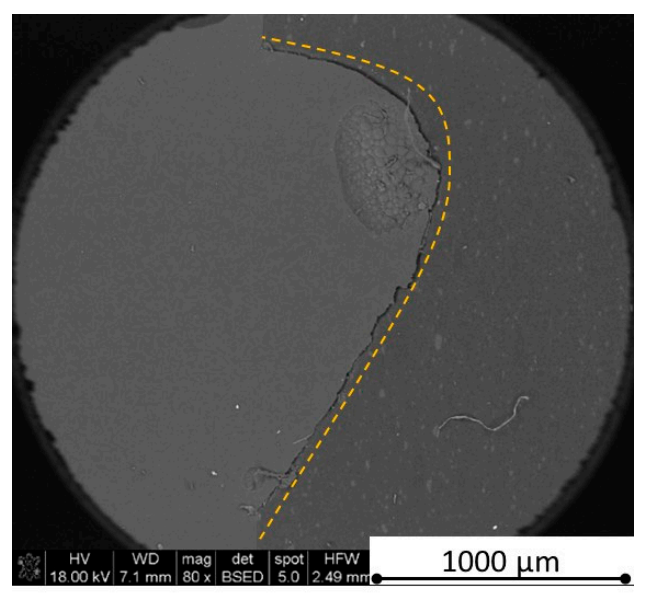

Figure 34. SEM observations of a $50 \mathrm{~W}$ laser processed $\mathrm{B}_{4} \mathrm{C}-8$ vol. $\% \mathrm{~h}-\mathrm{BN}$ in pressing direction (low surface roughness). 


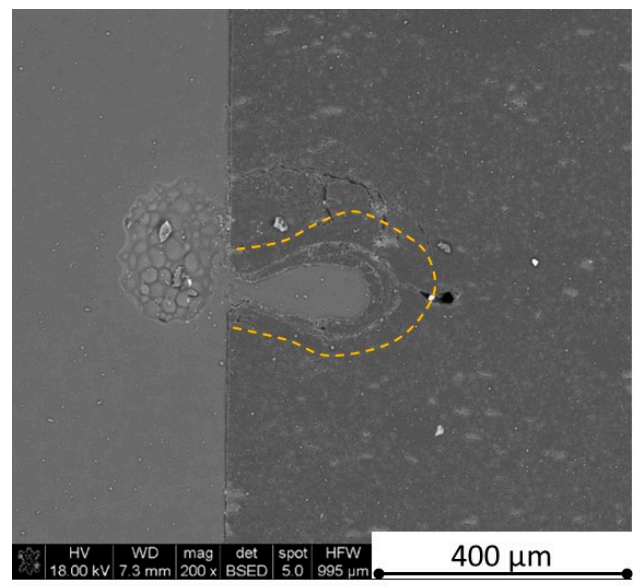

Figure 35. SEM observations of a $50 \mathrm{~W}$ laser processed $\mathrm{B}_{4} \mathrm{C}-8$ vol. $\% \mathrm{~h}-\mathrm{BN}$ in perpendicular direction (low surface roughness).

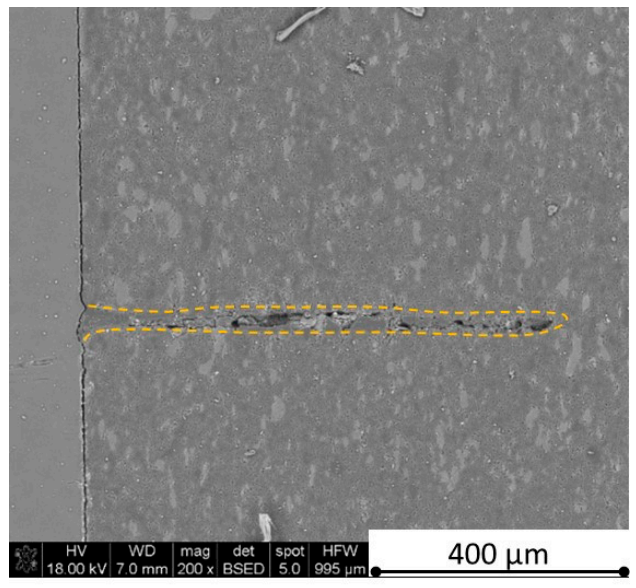

Figure 36. SEM observations of a $50 \mathrm{~W}$ laser processed $\mathrm{B}_{4} \mathrm{C}-32$ vol. $\% \mathrm{~h}-\mathrm{BN}$ in pressing direction (low surface roughness).

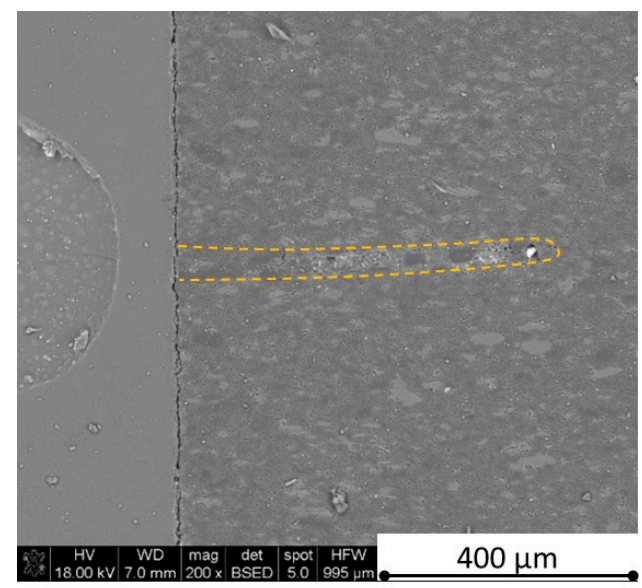

Figure 37. SEM observations of a $50 \mathrm{~W}$ laser processed $\mathrm{B}_{4} \mathrm{C}-32 \mathrm{vol} . \% \mathrm{~h}-\mathrm{BN}$ in perpendicular direction (low surface roughness).

The increase in h-BN content above 8 vol.\% causes the change of the laser cut shape, which is presented in Figures 30 and 31. For higher h-BN concentrations, the thermal anisotropy and h-BN 
agglomerates of the located porosity have a significant influence in laser processing. In perpendicular direction to the pressing axis (in-plane), the thermal diffusivity/conductivity is about $60 \%$ higher than in the pressing axis direction. It causes a heat transfer limitation in the out-of-plane direction and results in only 250-320 microns of processing depth for the rough surface sample. In this case, the ablation width is about 100 microns due to the heat transfer to the zone sides (Figure 32). There are no large cracks most likely due to the higher material porosity (Figure 3). Moreover, in the case of the low roughness polished sample with 32 vol.\% h-BN, narrow, crack free, and deep laser cuts were observed (Figures 36 and 37). Due to the argon flow some material stays inside the cut, but it can be removed by use of short pulse laser processing and a vacuum or under pressure conditions. In most of the laser treatment cases, the anisotropy of thermal properties leads to deeper and narrower cuts. For a low concentration of h-BN, cuts have the shape of a droplet.

The anisotropy of thermal properties, h-BN content, and material roughness also has an influence on the width end depth of the material cut. Comparing samples containing 0,8 , and 32 vol.\% of h-BN in the case of the material with high surface roughness which is higher than laser wavelength, the cut depth changes in following way: in parallel direction to pressing axis: $320 \mu \mathrm{m}$ for reference sample, $260 \mu \mathrm{m}$ for $8 \mathrm{vol} \% \mathrm{~h}-\mathrm{BN}$ and $310 \mu \mathrm{m}$ for $32 \mathrm{vol} \%$. Therefore, in this direction, the cut depth is typical as for the ceramic materials. It changes in perpendicular direction: $360 \mu \mathrm{m}$ for reference, $400 \mu \mathrm{m}$ for 8 vol.\% h-BN, and $720 \mu \mathrm{m}$ for 32 vol.\% h-BN. The width of the cut in the case of pure boron carbide can reach 200 microns in the case of material destruction. For $8 \% \mathrm{~h}-\mathrm{BN}$, the width of the cut is around 100 microns in the pressing direction and 70 microns in the perpendicular direction. For $32 \%$, the width of the cut is around 145 microns in the pressing direction and 40 microns in the perpendicular direction. By analyzing the dimension of the laser process ceramics with a surface roughness below the beam length, the reference sample shows the cut around $300 \mu \mathrm{m}$ in both material directions. For the high polished surface in the case of 8 vol. $\%$ h-BN addition, the measured depth is around $230 \mu \mathrm{m}$ and the width is 75 microns in perpendicular direction to the pressing axis, therefore, it is similar to the pressing direction. An interesting situation was noticed in the case of 32 vol.\% of $2 \mathrm{D}$ particles. In this case, for the well-polished surface the depth is $150 \mu \mathrm{m}$ higher than the perpendicular direction (610 $\mu \mathrm{m})$. The difference is also visible in the width, where $60 \mu \mathrm{m}$ is for the pressing direction and $40 \mu \mathrm{m}$ for the perpendicular direction to the pressing axis. Here, it can be suggested that the reflectivity and energy absorption rate should also be studied in the future.

Concerning the chemical phenomena taking place during laser processing, not only the decomposition of $\mathrm{h}-\mathrm{BN}$ (about $2500{ }^{\circ} \mathrm{C}$ ) should be taken under attention, but also the melting point of pure stoichiometric boron carbide $\left(2450^{\circ} \mathrm{C}\right)$ and eutectics in the system $\mathrm{B}_{4} \mathrm{C}-\mathrm{C}\left(2375{ }^{\circ} \mathrm{C}\right)$ and $\mathrm{B}_{4} \mathrm{C}-\mathrm{B}\left(2075^{\circ} \mathrm{C}\right)$ [29]. The confirmation of liquid phase and boron carbide formation in the cut tip is observed in Figure 32 and revealed by the EDS analysis showing only boron and carbon elements. The recrystallized phase is also visible in Figure 38.

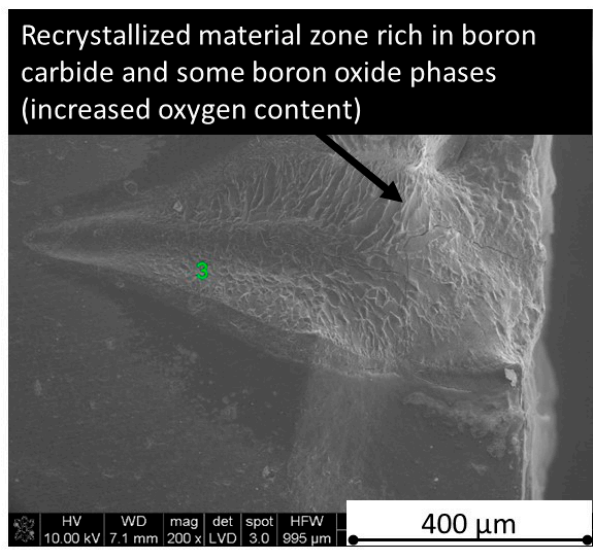

Figure 38. Cross-section of $\mathrm{B}_{4} \mathrm{C}-1 \% \mathrm{~h}-\mathrm{BN}$ process with $90 \mathrm{~W}$. 


\section{Conclusions}

During the research, anisotropic materials with a high relative density of over $94 \%$ were obtained by hot-pressing $\mathrm{B}_{4} \mathrm{C}$ with different amounts of h-BN addition. The laser processing conducted on all samples revealed a correlation between the h-BN content and shape of the performed cut. Additionally, the microstructure and thermal properties anisotropy is also dependent on the h-BN content in the samples. The porosity comes mostly from the h-BN agglomerates. A high anisotropy of the thermal expansion coefficient was observed between different material directions. It quickly reaches high values even for a low h-BN concentration, which can lead to material cracking during laser processing. The anisotropy of thermal conductivity and diffusivity was determined by LFA measurements. The thermal properties decrease in parallel direction to the pressing axis and slightly increase in perpendicular direction to the pressing axis. There is a high thermal properties anisotropy at low and high temperatures especially for the higher h-BN volume fraction. The observed high anisotropy of thermal properties influences the laser treatment of $\mathrm{B}_{4} \mathrm{C} / \mathrm{h}-\mathrm{BN}$ composites, resulting in deeper and narrower cuts after laser processing. The presence of a small amount of porosity in the material can protect composites from cracking during the laser action. The material surface roughness has little influence on laser processing and can be neglected. Future experiments employing the pulse working mode of laser and specific wave absorption coefficients are needed for a better understanding of the phenomenon during laser processing.

Author Contributions: All authors discussed and agreed upon the idea, and made scientific contributions. Conceptualization, P.R.; methodology, P.R., K.G., and K.M.; resources, P.R.; thermal expansion anisotropy investigation, P.R.; density changes versus temperature, P.R.; thermal diffusivity and conductivity, P.R. and K.G.; laser processing, P.R. and K.M.; other investigations, P.R., K.G., and K.M.; writing-original draft preparation, P.R.; writing-review, P.R.; writing-editing, P.R. and J.H.; visualization, P.R. and J.H.; supervision, P.R.; final approval, P.R. All authors have read and agreed to the published version of the manuscript.

Funding: This research was supported by the NCN statutory, project no. 16.16.160.557 of AGH University of Science and Technology in Krakow.

Conflicts of Interest: The authors declare no conflict of interest. The funders had no role in the design of the study; in the collection, analyses, or interpretation of data; in the writing of the manuscript, or in the decision to publish the results.

\section{References}

1. Werheit, H. Boron carbide: Consistency of components, lattice parameters, fine structure and chemical composition makes the complex structure reasonable. Solid State Sci. 2016, 60, 45-54. [CrossRef]

2. Hu, J.; Zhang, F.; Wang, W.; Fu, Z.; Zhang, J. Effect of impurities introduced by ball milling on hot pressed boron carbide. J. Eur. Ceram. Soc. 2019, 39, 2874-2881. [CrossRef]

3. Malmal Moshtaghiouna, B.; Gomez-Garcia, D.; Dominguez-Rodriguez, A.; Todd, R.I. Abrasive wear rate of boron carbide ceramics: Influence of microstructural and mechanical aspects on their tribological response. J. Eur. Ceram. Soc. 2016, 36, 3925-3928. [CrossRef]

4. Harichandran, R.; Selvakumar, N. Microstructure and mechanical characterization of $\left(\mathrm{B}_{4} \mathrm{C}+\mathrm{h}-\mathrm{BN}\right) / \mathrm{Al}$ hybrid nanocomposites processed by ultrasound assisted casting. Int. J. Mech. Sci. 2018, 144, 814-826. [CrossRef]

5. Gubernat, A.; Pichór, W.; Zientara, D.; Bućko, M.M.; Zych, Ł.; Kozień, D. Direct synthesis of fine boron carbide powders using expanded graphite. Ceram. Int. 2019, 45, 22104-22109. [CrossRef]

6. Liu, Y.; Tian, Q.; Wang, S.; Li, Z.; Duan, X.; Que, L.; Pei, C. Preparation of boron carbide nanosheets with high neutron-shielding properties based on reduced graphene oxide aerogel. Ceram. Int. 2020, 46, 18131-18141. [CrossRef]

7. Dasgupta, K. Role of carbon nanotubes in the ballistic properties of boron carbide/carbon nanotube/ultrahigh molecular weight polyethylene composite armor. Ceram. Int. 2020, 46, 4137-4141. [CrossRef]

8. Jianxin, D. Erosion wear of boron carbide ceramic nozzles by abrasive air-jets. Mat. Sci. Eng. A 2005, 408, 227-233. [CrossRef]

9. Jagannadham, K.; Watkins, T.R.; Lance, M.J.; Riester, L.; Lemaster, R.L. Laser physical vapor deposition of boron carbide films to enhance cutting tool performance. Surf. Coat. Tech. 2009, 203, 3151-3156. [CrossRef] 
10. Li, X.; Gao, Y.; Pan, W.; Zhong, Z.; Song, L.; Chen, W.; Yang, Q. Effect of hBN content on the friction and wear characteristics of $\mathrm{B}_{4} \mathrm{C}-\mathrm{hBN}$ ceramic composites under dry sliding condition. Ceram. Int. 2015, 41, 3918-3926. [CrossRef]

11. Han, F.; Wen, H.; Sun, J.; Wang, W.; Fan, Y.; Jia, J.; Chen, W. Tribological Properties of $\mathrm{Si}_{3} \mathrm{~N}_{4}$-hBN Composite Ceramics Bearing on GCr15 under Seawater Lubrication. Materials 2020, 13, 635. [CrossRef] [PubMed]

12. Ruh, R.; Kearns, M.; Zangvil, A.; Xu, Y. Phase and Property Studies of Boron Carbide-Boron Nitride Composites. J. Am. Ceram. Soc. 1992, 75, 864-872. [CrossRef]

13. Ruh, R.; Donaldson, K.Y.; Hasselman, D.P.H. Thermal Conductivity of Boron Carbide-Boron Nitride Composites. J. Am. Ceram. Soc. 1992, 75, 2887-2890. [CrossRef]

14. Li, X.; Gao, Y.; Song, L.; Yang, Q.; Wei, S.; You, L.; Zhou, Y.; Zhang, G.; Xu, L.; Yang, B. Influences of hBN content and test mode on dry sliding tribological characteristics of B4C-hBN ceramics against bearing steel. Ceram. Int. 2018, 44, 6443-6450. [CrossRef]

15. Li, X.; Gao, Y.; Yang, Q. Sliding tribological performance of $\mathrm{B}_{4} \mathrm{C}-\mathrm{hBN}$ composite ceramics against AISI 321 steel under distilled water condition. Ceram. Int. 2017, 43, 14932-14937. [CrossRef]

16. Li, X.; Gao, Y.; Wei, S.; Yang, Q. Tribological behaviors of $\mathrm{B}_{4} \mathrm{C}-\mathrm{hBN}$ ceramic composites used as pins or discs coupled with $\mathrm{B}_{4} \mathrm{C}$ ceramic under dry sliding condition. Ceram. Int. 2017, 43, 1578-1583. [CrossRef]

17. Li, X.; Gao, Y.; Wei, S.; Yang, Q.; Zhon, Z. Dry sliding tribological properties of self-mated couples of $\mathrm{B}_{4} \mathrm{C}-\mathrm{hBN}$ ceramic composites. Ceram. Int. 2017, 43, 162-166. [CrossRef]

18. Li, X.; Gao, Y.; Yang, Q.; Pan, W.; Li, Y.; Zhong, Z.; Song, L. Evaluation of tribological behavior of $\mathrm{B}_{4} \mathrm{C}-\mathrm{hBN}$ ceramic composites under water-lubricated condition. Ceram. Int. 2015, 41, 7387-7393. [CrossRef]

19. Li, X.; Gao, Y.; Pan, W.; Wang, X.; Song, L.; Zhong, Z.; Wu, S. Fabrication and characterization of B ${ }_{4}$ C-based ceramic composites with different mass fractions of hexagonal boron nitride. Ceram. Int. 2015, 41, 27-36. [CrossRef]

20. Pan, W.; Gao, Y. Tribological behavior of B4C/hBN ceramic composites coupled with grey iron under the lubrication of emulsion. Mater. Res. Express 2018, 5, 066512. [CrossRef]

21. Rutkowski, P. Mechanical and thermal properties of hot pressed $\mathrm{B}_{4} \mathrm{C}-\mathrm{Cr}_{3} \mathrm{C}_{2}-\mathrm{hBN}$, materials. J. Eur. Ceram. Soc. 2014, 34, 3413-3419. [CrossRef]

22. NIST Chemistry WebBook. Available online: http://webbook.nist.gov (accessed on 2 October 2020).

23. Saleem, A.; Zhang, Y.; Gong, H.; Majeed, M.K.; Jing, J.; Lin, X.; Zeeshan Ashfaq, M. Enhanced thermal conductivity and mechanical properties of a GNP reinforced $\mathrm{Si}_{3} \mathrm{~N}_{4}$ composite. RSC Adv. 2019, 9, 39986. [CrossRef]

24. Tanimoto, M.; Yamagata, T.; Miyata, K.; Ando, S. Anisotropic Thermal Diffusivity of Hexagonal Boron Nitride-Filled Polyimide Films: Effects of Filler Particle Size, Aggregation, Orientation, and Polymer Chain Rigidity. ACS Appl. Mater. Interfaces 2013, 5, 4374-4382. [CrossRef] [PubMed]

25. Wood, C.; Zoltan, A.; Emin, D.; Gray, P.E. Thermal conductivity behavior of boron carbides. In Thermal Conductivity 18; Springer: Boston, MA, USA, 1985. [CrossRef]

26. Black, I.; Chua, K.L. Laser cutting of thick ceramic tail. Opt. Technol. 1997, 29, 193-205. [CrossRef]

27. Rakshit, R.; Kumar Das, A. A review on cutting of industrial ceramic materials. Precis. Eng. 2019, 59, 90-109. [CrossRef]

28. Zhang, X.; Pfeiffer, S.; Rutkowski, P.; Makowska, M.; Kata, D.; Yang, J.; Graule, T. Laser cladding of manganese oxide doped aluminum oxide granules on titanium alloy for biomedical applications. Appl. Surf. Sci. 2020, 520,1-11. [CrossRef]

29. The Phase Equilibria Diagrams PC Database; Version 4.0; National Institute of Standards and Technology: Gaithersburg, MD, USA, 2019.

Publisher's Note: MDPI stays neutral with regard to jurisdictional claims in published maps and institutional affiliations. 